\title{
Captura de plusvalías, regularización de edificios y aglomeraciones turísticas en Guadalajara
}

\section{Value capture, regularization of buildings, and tourist agglomerations in Guadalajara}

\author{
Basilio Verduzco-CháVez* \\ María Basilia-Valenzuela*
}

\begin{abstract}
This article analyzes an impact fee program implemented in Guadalajara, Jalisco, to regularize urban projects built violating the existing zoning code. To identify the program contributions to the formation of business and tourist districts and its effciency as an instrument for value capture, the program design and the progress achieved in its implementation between March 2016 and September 2017 are evaluated. It is concluded that the program makes poor contributions to the formation of tourist agglomerations and business districts because it presents failures that undermine its efficiency as an instrument of value capture that helps to reduce social inequality in the city.
\end{abstract}

Keywords: value capture, impact fees, agglomeration economies, tourist districts, public policy.

\section{Resumen}

Este artículo evalúa un programa de cuotas de impactos del municipio de Guadalajara, Jalisco, con el que se regularizan acciones urbanísticas construidas violando la zonificación vigente. Para identificar las aportaciones del programa a la formación de distritos de negocios y turismo y su eficiencia como instrumento de captura de plusvalía, se evalúan el diseño del programa y sus avances entre marzo de 2016 y septiembre de 2017. Se concluye que el programa contribuye pobremente a formar aglomeraciones turísticas y distritos de negocios, debido a que contiene sesgos e ineficiencias como instrumento de captura de plusvalía que ayude a reducir la desigualdad social urbana.

Palabras clave: captura de plusvalía, cuotas de impacto, economías de aglomeración, distritos turísticos, política pública. 


\section{Introducción}

Los gobiernos locales de América Latina han incrementado el uso de instrumentos de captura de plusvalía para fines de política urbana (Smolka y Amborski, 2003; Smolka, 2013). Entre las herramientas usadas se encuentran las contribuciones por mejoras, las exacciones, cargos o cuotas de construcción y el financiamiento por incremento de impuestos (Blanco et al., 2016). Con éstas se procuran objetivos como el impulso a nuevos desarrollos, hacer frente a la transición de áreas urbanas consolidadas que enfrentan cambios de uso de suelo, densificación, congestionamiento vial, deterioro de infraestructuras, entre otros cambios típicos de áreas centrales de ciudades en expansión que experimentan procesos de reestructuración (López-Morales y Meza-Corvalán, 2015). Uno de los instrumentos más usados es el cobro de cuotas de impacto o derechos de desarrollo (development impact fees) (Brueckner, 1997; Murphy y Murphy 2004). Para usar este instrumento es necesario conocer los valores del suelo en el mercado (Sandroni, 2016), pero puede ser aplicado ex ante, o bien, como mecanismo de corrección para proyectos inmobiliarios construidos a partir de la violación de alguna norma.

Este artículo evalúa el Programa de Compensación, Indemnización y Mitigación por Acciones Urbanísticas (CIMAU) creado mediante una reforma al reglamento de gestión del desarrollo urbano del municipio de Guadalajara, Jalisco, publicada el 2 de marzo de 2016 en la Gaceta municipal (Ayuntamiento de Guadalajara, 2016). La evaluación se concentra en dos beneficios potenciales del programa: su contribución a la consolidación de economías de aglomeración en distritos de negocios y turísticos, lo cual se considera relevante porque el turismo y los servicios se han convertido en motores del desarrollo urbano en México; y la eficiencia de las cuotas de impactos como instrumento de captura de plusvalía que contribuye a reducir la desigualdad social urbana. Se usa información proveniente de los decretos que regularizan edificios publicados en la Gaceta municipal del 3 de marzo de 2016 al 19 de septiembre de 2017 (Ayuntamiento de Guadalajara, 2016-2017).

Este artículo está organizado en cinco secciones. La primera revisa la literatura sobre el uso de mecanismos de captura de plusvalía. La segunda, describe la formación de distritos de negocios y turismo en Guadalajara en el contexto del desarrollo metropolitano. La tercera propone una metodología de evaluación del programa con el criterio de centralidad —entendida como facilidades de acceso a ciertos polígonos de la ciudad que es donde normalmente se forman aglomeraciones- y el criterio de eficiencia de captura de plusvalías. La cuarta parte presenta los resultados de la evaluación. El artículo concluye que el programa CIMAU tiene 
sesgos y deficiencias que disminuyen sus contribuciones a la formación de aglomeraciones y reducen su eficiencia en la disminución de la desigualdad.

\section{Revisión de literatura sobre captura de plusvalía}

En el ámbito urbano se generan plusvalías producidas socialmente, por lo que el valor de suelo y fincas no depende plenamente de las decisiones individuales de los inversionistas o propietarios. La existencia de plusvalías está asociada, entre otros factores, a la dotación de infraestructura y servicios, la regulación de usos de suelo y el cuidado del entorno e imagen urbana (Smolka, 2013). La apropiación de plusvalías es una fuerza motriz para explicar el proceso de desarrollo urbano y la localización de actividades económicas en el entorno construido. La idea de capturar plusvalías mediante políticas públicas tiene sus raíces en la teoría de la renta urbana que propuso William Alonso a principios de la década de los años sesenta del siglo pasado (Alonso, 1960 y 1964). Según esta teoría, el valor de la tierra se crea y distribuye en forma desigual en la ciudad y tiende a concentrarse en las áreas con mayor accesibilidad y más amenidades. La literatura crítica sobre teoría de la renta del suelo ve a la centralidad y las ventajas de localización como construcciones sociales que generan valor al suelo y como acciones ajenas a los propietarios del mismo. Ese valor adicional, no adjudicado a las características físicas del terreno o a la inversión del propietario, es considerado una plusvalía que corresponde a la comunidad (Fainstein, 2012).

Los gobiernos usan instrumentos de captura de plusvalía para financiar el desarrollo urbano y dirigirlo hacia objetivos socialmente deseables, como el combate a la pobreza o la disminución de la desigualdad (Blanco et al., 2016), el mejoramiento de la infraestructura mediante pagos en efectivo o aportaciones en especie (Vejarano, 2008), o el financiamiento de obras de transporte en zonas metropolitanas (Sandroni, 2011). Este procedimiento puede usarse, con ciertas reservas, para inducir la formación de aglomeraciones de negocios, entendidas como mezclas de unidades económicas que se benefician de su proximidad, en distritos centrales (Fischer y Sclar, 2016) las cuales pueden comprender hoteles y otro tipo de empresas (Peiró-Signes et al., 2014); o para financiar trasporte masivo aeropuerto-centro de la ciudad (Neville et al., 2015); impulsar equipamientos deportivos, distritos culturales o apoyar distritos urbanos, entendidos como polígonos de la ciudad con algún reconocimiento o delimitación para fines administrativos, de mercadotecnia o de política pública, y proyectos de renovación urbana demandados por turistas en busca de 
experiencias (McIntosh, 1999; Smolka, 2013; Cuenya, 2016 y Monterrubio, 2017).

Hay varias formas de utilizar estos instrumentos, asociadas a metas y objetivos de desarrollo (Hui et al., 2004). Amsterdam ha intentado densificar y diversificar el uso del suelo mediante un sistema de renta a perpetuidad (OCDE, 2017); Delaware introdujo un impuesto a los servicios de hospedaje para financiar proyectos de manejo de playas (Parsons y Noailly, 2004), y Mumbai ha utilizado contratos de arrendamiento por 80 años para inducir la construcción de hoteles, centros de convenciones y edificios comerciales en zonas específicas (Government of India, 2017). A nivel internacional se cuestiona si los mecanismos de captura de plusvalía pueden contribuir a objetivos de justicia o sólo de eficiencia, dados los sesgos en favor de ésta (Cuenya, 2016).

La teoría sugiere que es posible impulsar aglomeraciones con tarifas compensatorias (Aitchison et al., 2000 y Shoval, 2006). Su aplicación plantea serios problemas metodológicos (Peiró-Signes et al., 2014), entre los que destacan: 1. El establecimiento de precios del suelo y 2. La fijación de las tarifas establecidas para el otorgamiento de derechos de edificación (Terrill, 2017). Asimismo se han detectado consecuencias: 1. El diseño pobre de cuotas por impactos puede distorsionar los mercados de suelo (Peterson, 2008); 2. Las políticas del gobierno local incrementan el valor de las propiedades porque dan certidumbre a los desarrolladores (Jeong, 2006 y Christensen, 2011); 3. El interés por la eficiencia opaca el tema de la distribución y resta efectividad en la disminución de desigualdad social o en la tarea de garantizar el derecho a la ciudad (Fainstein, 2012); 4. La zonificación orienta la localización de industrias, pero está expuesta a presiones políticas (Cruz-Muñoz, 2016).

La captura de plusvalías se justifica cuando se considera que el derecho de desarrollo es un bien público y no un bien privado. Los propietarios aceptan hacer pagos de derechos de desarrollo si pueden transferir al consumidor los pagos realizados (Huffman et al., 1988 y Singell y Lillydahl, 1990) lo que se refleja en precios de vivienda más altos (Skaburskis y Qadeer, 1992); o cuando el valor de las edificaciones en el mercado - convergencia de la disposición de compradores y vendedores (Nilsson, 2011)_, supera la suma de tarifas impuestas en los programas de regularización, costos de construcción y, en general, los costos de transacción para el desarrollador.

Las cuotas de impacto son una forma de renta diferencial que se puede pagar por extensión en el porcentaje de ocupación del predio o por intensificación de su uso (Haila, 2015). Para el establecimiento de pagos, normalmente se toma en cuenta la existencia de Coeficientes de ocupación del suelo (COS) que miden porcentaje edificable de un predio; y Coefi- 
cientes de utilización del suelo (CUS) que miden densidad de uso. Las cuotas de impactos dan lugar a un proceso de densificación, debido a que el cambio de valor de suelo es un factor que influye en las ganancias de los desarrolladores en la medida que altera los equilibrios entre costos de construcción y valor de las propiedades. La aplicación de estos instrumentos está expuesta a variaciones contextuales. Cada ciudad plantea nuevos retos.

\section{Economías de aglomeración, centralidad urbana y distritos turísticos en Guadalajara}

La ciudad de Guadalajara, capital del estado de Jalisco ubicado en el Occidente de México, es el corazón de una zona metropolitana formada por nueve municipios. En 2015, la metrópoli tenía una población total de 4,855,222 habitantes, de los cuales 1,460, 148 corresponden al municipio de Guadalajara (cuadro 1). El crecimiento de la ciudad ha dado lugar a diversas aglomeraciones económicas especializadas y distritos de negocios y turismo que se benefician de la ubicación central del municipio. Esta dinámica fue capturada, con algunas deficiencias, en el Plan de Ordenamiento Territorial Metropolitano de 2016 (en lo sucesivo, llamado POTMET-2016) que reconoció la existencia de cuatro niveles de centralidad urbana, tomando en cuenta criterios de consolidación de funciones urbanas, infraestructura, escala de proyectos que pueden albergar, conectividad y de política de poblamiento: a) central metropoli-

\section{Cuadro 1}

Población total de los municipios de la Zona Metropolitana de Guadalajara (ZMG), 2015

\begin{tabular}{|c|c|c|}
\hline Municipio & Población & Porcentaje en la ZMG \\
\hline El Salto & 183,437 & 3.78 \\
\hline Guadalajara & $1,460,148$ & 30.07 \\
\hline Ixtlahuacán de los Membrillos & 53,045 & 1.09 \\
\hline Juanacatlán & 17,955 & 0.37 \\
\hline Tlajomulco & 549,542 & 11.32 \\
\hline Tlaquepaque & 664,193 & 13.68 \\
\hline Tonalá & 536,111 & 11.04 \\
\hline Zapopan & $1,322,272$ & 27.23 \\
\hline Zapotlanejo & 68,519 & 1.41 \\
\hline Total & $4,855,222$ & 100.00 \\
\hline
\end{tabular}

Fuente: IIEG, 2015. 
tana con grado de consolidación 1, b) centralidad periférica con tres grados de consolidación 2,3 y $4 ; c$ ) centralidad satélite con grados de consolidación 3 y 4 ; y d) centralidad emergente sin grados de consolidación reconocidos. Usando esta clasificación, el POTMET-2016 identificó tres áreas con centralidad metropolitana (Centro de Guadalajara, Centro de Zapopan y Centro de Tlaquepaque), 15 áreas con centralidad periférica en las que el municipio de Guadalajara participa de la siguiente manera: dos de grado de consolidación 2 (Expo-Chapalita y Oblatos); y, cinco de grado 3, que incluyen a Providencia, Huentitán y Parque Solidaridad-Tetlán, identificadas más adelante en la figura 2 (Imeplan, 2016).

Las centralidades propuestas en el POTMET-2016 no corresponden claramente al comportamiento del mercado inmobiliario, el cual ha seguido un patrón de segregación social oriente-poniente, dando lugar a centralidades de negocios y de turismo en el poniente del centro tradicional de Guadalajara.

El gobierno del estado y el gobierno local han intentado contribuir a la conformación de distritos turísticos en diversas ocasiones, a la vez que mantienen el centro como principal nodo de actividades administrativas. El primer intento ocurrió en los ańos sesenta del siglo XX, cuando se construyeron los edificios del Hotel Hilton (1961, hoy Misión Carlton) y Condominio Guadalajara (1963) en las inmediaciones del Parque Agua Azul, ubicado al sur del municipio en donde se encontraban también la central de autobuses y la estación de ferrocarril. Posteriormente, el mercado inmobiliario y las obras de infraestructura realizadas para facilitar el crecimiento de Guadalajara, impulsaron el surgimiento de zonas que han ganado centralidad como ocurrió con Plaza del Sol, construida en 1969, en cuyas inmediaciones se construyó más tarde Expo Guadalajara; o más recientemente otros distritos como Chapultepec, ubicado sobre colonias residenciales en el poniente de la ciudad que fueron el asentamiento de clases pudientes desde principios del siglo XX; Providencia, que se formó como fraccionamiento suburbano en los años setenta; y el más reciente en el municipio de Zapopan conocido como Andares-Puerta de Hierro. De esta manera, en el poniente de la ciudad central de la metrópoli se ha forjado un gran polígono de turismo de negocios, que se desprende hacia el sur desde la Glorieta Colón en la confluencia de las avenidas López Mateos y Américas y conecta los distritos de Providencia, Chapultepec y Expo Guadalajara-Chapalita (figura 2).

Las nuevas aglomeraciones de negocios y turismo han generado múltiples controversias derivadas de las violaciones a los planes de desarrollo urbano y a las normas de edificación, contaminación ambiental por ruido, afectaciones a fincas por externalidades durante la construcción de 
nuevos edificios, afectaciones al patrimonio familiar por sombra, inseguridad, pérdida de confort y pérdida de privacidad. Respondiendo a esos conflictos en 2016, el nuevo gobierno municipal emprendió la tarea de revisar violaciones en la construcción de edificios y tomar medidas para que los desarrolladores internalizaran parte de sus impactos, generando con ello recursos para financiar acciones de desarrollo. Enseguida se presentan resultados de la evaluación a este programa.

\section{Criterios y metodología de evaluación del Programa CIMAU}

En Guadalajara, cada tres años la actualización de planes parciales de desarrollo urbano entra en un ciclo de hechura, debate e interrupción del proceso. Desde 2003 y hasta diciembre de 2017 no se habían actualizado los planes parciales de desarrollo urbano. Los planes aprobados en 2015 fueron impugnados en el Tribunal Administrativo del Estado y su implementación quedó interrumpida. Esa situación ha derivado en procedimientos de aprobación proyecto por proyecto lo que implica un incremento de los incentivos de corrupción y da lugar a violaciones de las reglas existentes en materia de edificación, uso de suelo, imagen urbana y manejo de impactos urbanos y ambientales. Ante esta situación, el gobierno municipal, instaurado a finales de 2015 con la elección de Enrique Alfaro del partido Movimiento Ciudadano, emprendió una política de regularización mediante la adición del artículo 4 Ter al Reglamento de Gestión del Desarrollo Urbano para el Municipio de Guadalajara. La reforma "establece la compensación, indemnización y mitigación como mecanismos para identificar o determinar los daños causados a la ciudad por acciones urbanísticas cuya autorización o realización fueron sin apego a las normas establecidas en este reglamento" (Ayuntamiento de Guadalajara, 2016). El análisis del diseño, contenido en las disposiciones administrativas del programa, revela el potencial de capturar plusvalía y de influir en la distribución socio-espacial en el municipio de los beneficios del desarrollo metropolitano.

Si bien el programa CIMAU no se propone explícitamente como un programa gubernamental de captura de plusvalías derivadas de las aglomeraciones, sino como un programa de compensación por impactos de edificaciones que no respetaron la densidad vigente en planes de uso de suelo, su aplicación selecciona como áreas objetivos las aglomeraciones emergentes en la ciudad. Por lo tanto, puede ser interpretado como un programa de captura de plusvalías, y las cuotas pueden ser asumidas por el desarrollador inmobiliario como un costo adicional a los de construcción, lo que implica cambios en la relación valor de la propiedad/densidad que 
pueden ser transferidos al consumidor. El programa se justifica para densidades en las que el valor de la propiedad supera con mucho los costos de construcción, por lo tanto, abre oportunidades de aglomeración asociadas a la distribución territorial de la regulación de uso de suelo. El programa de cuotas de impactos puede tener efectos más positivos, si las tarifas consideradas son coherentes con una regulación de usos de suelo orientada a procurar la consolidación de distritos de negocios y turismo para aprovechar al máximo las economías de aglomeración competitiva.

\subsection{Metodología de evaluación del programa}

La siguiente evaluación abarca acciones urbanísticas regularizadas en un periodo de 19 meses. Por ello, más que una evaluación integral del programa, se analizan aspectos de su diseño y proceso de implementación a partir de dos grandes criterios: a) la pertinencia del diseño como promotor de conformación de centralidades urbanas que sirvan de base para la consolidación de distritos turísticos (criterio de centralidad urbanoturística) y, b) la eficiencia de los instrumentos contemplados en el programa para lograr captura de plusvalías que ayuden a consolidar un desarrollo urbano menos desigual y financien la consolidación de distritos centrales (criterio de eficiencia de captura de plusvalías). La evaluación parte de dos planteamientos hipotéticos:

Hipótesis 1: El programa CIMAU contribuye a la formación de distritos de negocios y turismo competitivos, si es coherente con una zonificación de suelo que favorece formaciones de áreas centrales, economías de aglomeración y de distritos urbanos en la zona metropolitana donde los turistas tienen condiciones para coproducir sus experiencias memorables.

Hipótesis 2: El programa CIMAU es eficiente en la recuperación de plusvalías, si puede ayudar a compensar impactos directos en donde se ubican las edificaciones regularizadas, a financiar el desarrollo de infraestructura metropolitana y a promover mejoras en la equidad social mediante inversiones en zonas menos desarrolladas. En la evaluación empírica, se usa un enfoque metodológico que combina análisis cuantitativo y georreferenciado de información derivada del diseño y la implementación del programa.

\section{Resultados de la evaluación}

El programa CIMAU está dirigido a "identificar y determinar los daños causados a la ciudad por las acciones urbanísticas iniciadas antes del $1 \mathrm{de}$ 
octubre de 2015, cuya autorización o realización fueron sin apego a las normas en materia urbana y de medio ambiente, y determinar el procedimiento para la compensación, indemnización y mitigación, conjunta o separada, de dichas acciones urbanísticas" (Ayuntamiento de Guadalajara, 2016: Disposiciones Administrativas art. 1).

El diseño del programa contempla una estructura de implementación con la participación de las diferentes dependencias del gobierno como instancias con capacidad de evaluación de impactos, y de las distintas fracciones partidistas como instancias políticas para lograr el consenso necesario. Con ese proceso, el gobierno asume un control centralizado de la regularización y deja abierta la puerta a los interesados para que se acerquen al gobierno municipal para resolver su situación.

Un componente central del programa es la identificación y valoración de impactos urbanos y ambientales causados por las edificaciones. No obstante, la metodología para la identificación, caracterización de impactos y para determinar la compensación, indemnización y mitigación procedentes es demasiado simple y no toma en cuenta los intereses de los grupos sociales afectados. Al mismo tiempo, el procedimiento es demasiado complicado para que los involucrados puedan entender los cálculos realizados o los criterios usados por las autoridades municipales para predecir impactos de los proyectos. El reglamento establece que las disposiciones de carácter técnico del programa no constituyen una zonificación ni modifican los planes parciales existentes, pero su aplicación retrospectiva, regulariza acciones no contempladas en dichos planes por lo que, al igual que un plan, tiene efectos distributivos de rentas y tiende a favorecer a quienes racionalmente tomaron la decisión de violar la normatividad establecida en los planes.

Las reglas del programa dan lugar a las siguientes situaciones y tarifas (figura 1).

a) La situación 1 (T1) que corresponde a construcciones con un Coeficiente de utilización del suelo (CUS) superior a lo contemplado en los planes vigentes aprobados en 2003, pero inferior o igual al Coeficiente de utilización del suelo incrementado (ICUS) que, sumado al CUS vigente, establece el CUS señalado en el plan parcial suspendido de 2015. En esta situación se fija una tarifa establecida en la Ley de Ingresos, tomando en cuenta la ubicación del predio.

b) La situación 2 (T2) que corresponde a construcciones que rebasaron el CUS del plan suspendido de 2015. Para quienes se encuentran en esta situación, se propone cobrar una tarifa por metro 
cuadrado excedido equivalente al valor catastral de los predios en la zona en cuestión.

La lógica del diseño puede ser usada para generar dos situaciones adicionales, no contempladas que son las siguientes (T3 y T4).

c) La situación 3 (T3) que corresponde a construcciones con un Coeficiente de ocupación del suelo (COS) superior a lo señalado en los planes vigentes aprobados en 2003, pero inferior o igual al Coeficiente de ocupación del suelo incrementado (ICOS) que, sumado al COS vigente, establece el COS del plan parcial suspendido de 2015.

d) La situación 4 (T4) que corresponde a construcciones que rebasaron el COS contemplado en el plan suspendido de 2015.

Lo anterior significa que el valor de las compensaciones a pagar por una edificación se debería estimar como sigue:

$$
\mathrm{Ct}=\mathrm{T} 1+\mathrm{T} 2+\mathrm{T} 3+\mathrm{T} 4
$$

Sin embargo, en la práctica sólo se aplican dos tarifas principales en función al coeficiente de utilización del suelo: T1 y T2. Conviene tomar en cuenta esta tipología de tarifas porque en la contrastación empírica, presentada más adelante, se observan algunas inconsistencias en la aplicación.

\section{Figura 1}

Tarifas contempladas para los edificios que participan en el Programa de Compensación, Indemnización y Mitigación por Acciones Urbanísticas

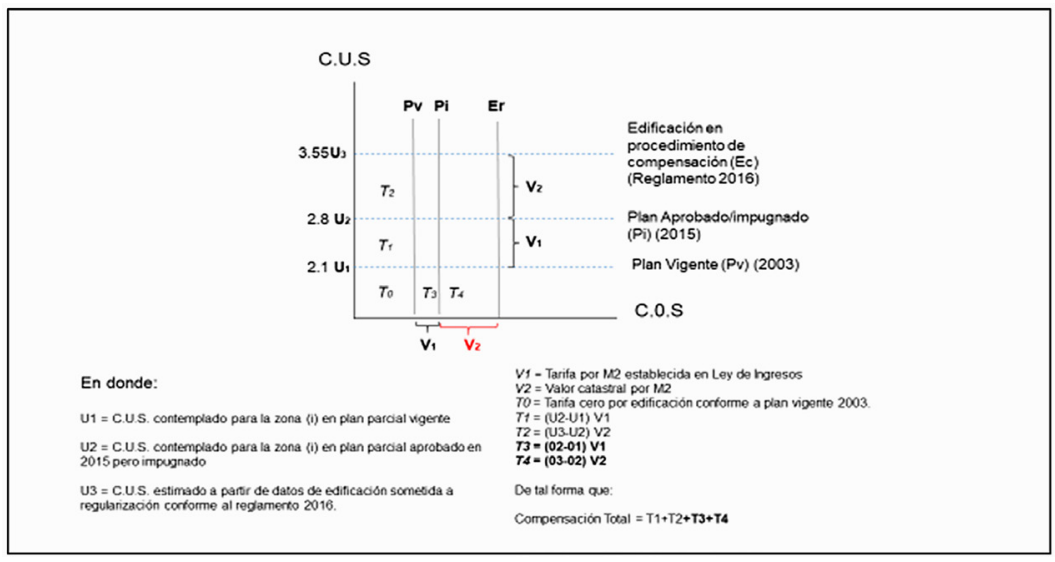

Fuente: elaboración propia con base en las disposiciones administrativas del Programa CIMAU (Ayuntamiento de Guadalajara, 2016). 


\subsection{Evaluación con el criterio de centralidad urbano-turística}

En la evaluación del programa de compensaciones con el criterio de centralidad urbano turística se consideran las previsiones contempladas en el diseño, que tienen como propósito influir directamente sobre la geografía de la distribución de usos de suelo en la ciudad. A partir de la teoría de economías de aglomeración y estudios sobre el advenimiento del turismo de experiencias en la cotidianidad de las ciudades (Jiménez-Martínez, 2017) se puede verificar si el programa contribuye a lograr la consolidación de centros y subcentros de negocios con servicios turísticos competitivos y su coherencia con la regulación de usos de suelo.

Enseguida, se revisa la geografía de usos de suelo que intenta inducir este programa a partir del análisis de los "Tabuladores Base, para el Cálculo de la Compensación o Indemnización del Excedente Constructivo”. Estos tabuladores son muy interesantes para la evaluación por diversas razones. En primer lugar, toman como base las regulaciones contempladas en los planes parciales suspendidos o impugnados de 2015, no las regulaciones contempladas en los planes vigentes. Ese hecho institucionaliza cualquier sesgo que hubiera existido en los planes mencionados, cuya suspensión los dejó fuera del escrutinio del público y los expertos en cuanto a sus contribuciones para ordenar el desarrollo urbano y la conformación de distritos de negocios y turismo competitivos.

Los indicadores propuestos son Superficie mínima del lote, Coeficiente de ocupación del suelo (COS) —entendido como el porcentaje de un lote sobre el que se puede desplantar una vivienda-, Coeficiente de utilización de suelo (CUS) - el cual se refiere a un parámetro que multiplicado por el tamaño del predio establece la cantidad de metros cuadrados que se pueden edificar en ese predio-, Coeficiente de ocupación del suelo incrementado (ICOS), Coeficiente de utilización del suelo incrementado (ICUS), Altura -se refiere a la altura máxima permitida de la construcción, expresada en niveles-, e Índice de edificación (IDE) -expresa el número máximo de viviendas permitidas al dividirse la superficie del lote entre su valor (Ayuntamiento de Guadalajara, 2016).

En la evaluación con el criterio de centralidad, se han utilizado sólo los aspectos regulados siguientes: primero, la distribución de los usos comerciales y de servicios que dan lugar a aglomeraciones de negocios que usan intensivamente el suelo, a saber: Uso Mixto Distrital en sus niveles tres (MD-3) y cuatro (MD-4); Mixto Central nivel cuatro (MC-4); Comercial y de Servicios nivel Distrital (CS-D), o Comercial y de Servicios nivel Central (CS-C), Comercial y Servicios a nivel Regional (CS-R); y, segundo, la distribución de todos los usos hoteleros. Con esos criterios, se obtuvo 
una base de datos de 317 zonas que conforman el universo de zonas reguladas con las que se puede inducir la conformación de distritos urbanos como subcentros metropolitanos y espacios para albergar la base económica competitiva de la ciudad. Los usos fueron ordenados siguiendo criterios generales de la teoría del lugar central, que supone la existencia de distintas jerarquías de centralidad en un espacio metropolitano.

Los resultados se presentan en la gráfica 1 . En ella se puede ver que el número de zonas por uso sugiere una pirámide de centralidad en donde CS-R está en el tope de la jerarquía de usos de suelo, por lo cual sólo hay una zona. No obstante, una primera inconsistencia con la planeación existente es que dicha zona está ubicada en el Distrito Huentitán, Subdistrito Zoológico, que es una zona de centralidad periférica con grado de consolidación 3, según el POTMET-2016. Se puede ver que el número de zonas va creciendo a medida que disminuye la aportación del uso a la construcción de distritos centrales hasta llegar al uso MD-4. A partir de ahí, el modelo empieza a mostrar otras inconsistencias, pues hay más zonas con uso MD-4 que MD-3, y otras zonas que aportan poco a la centralidad, también son consideradas en la conformación de distritos turísticos a otorgárseles usos hoteleros.

Para tener una visión panorámica del modelo de centralidades propuesto en el programa evaluado, se hizo una georreferenciación de las zonas contempladas según usos de mayor intensidad permitidos. Aquí se usa una escala inversa a lo propuesto en el POTMET-2016, para facilitar la lectura del mapa se identifican cuatro niveles de centralidad en donde $4=$ centralidad alta, $3=$ centralidad media, $2=$ centralidad baja, $1=$ centrali-

\section{Gráfica 1}

Total de zonas que participan en el programa CIMAU para usos seleccionados con potencial de contribuir a la formación de centralidades con economías de aglomeración

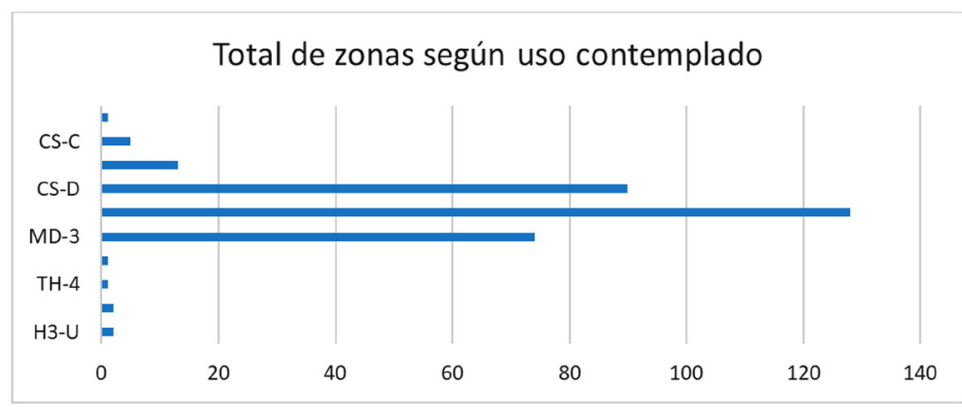

Fuente: elaboración propia a partir de las disposiciones administrativas del Programa CIMAU (Ayuntamiento de Guadalajara, 2016). 
dad muy baja. De acuerdo con el criterio de formación de centralidades utilizado para la evaluación, se esperaría una distribución relativamente concéntrica de las zonas en torno a puntos con mayor accesibilidad.

La figura 2 muestra la brecha entre la normatividad usada para el programa y la permisividad dada a la densificación mediante compensación. Por un lado, los edificios regularizados, sobre todo los de mayor altura y con más metros regularizados, se ubican en la parte poniente de la ciudad en las inmediaciones de la avenida López Mateos desde sus inicios en el norte de la ciudad en la Glorieta Colón, hasta Chapalita.

Mientras tanto, las áreas que favorecen la centralidad tienden a ubicarse en puntos alejados entre sí, como son la zona del mercado de abastos y del zoológico. Asimismo, el programa CIMAU reconoce usos hoteleros como sujetos a regularización prácticamente sólo en el poniente de la ciudad en distritos gastronómico-turísticos como los que se están formando en la zona de Providencia y de Chapultepec con lo cual agudiza la desigualdad social oriente-poniente.

\section{Figura 2}

\section{Distribución geográfica de los usos de suelo considerados en el programa CIMAU para impulsar centralidades y ubicación de edificios regularizados}

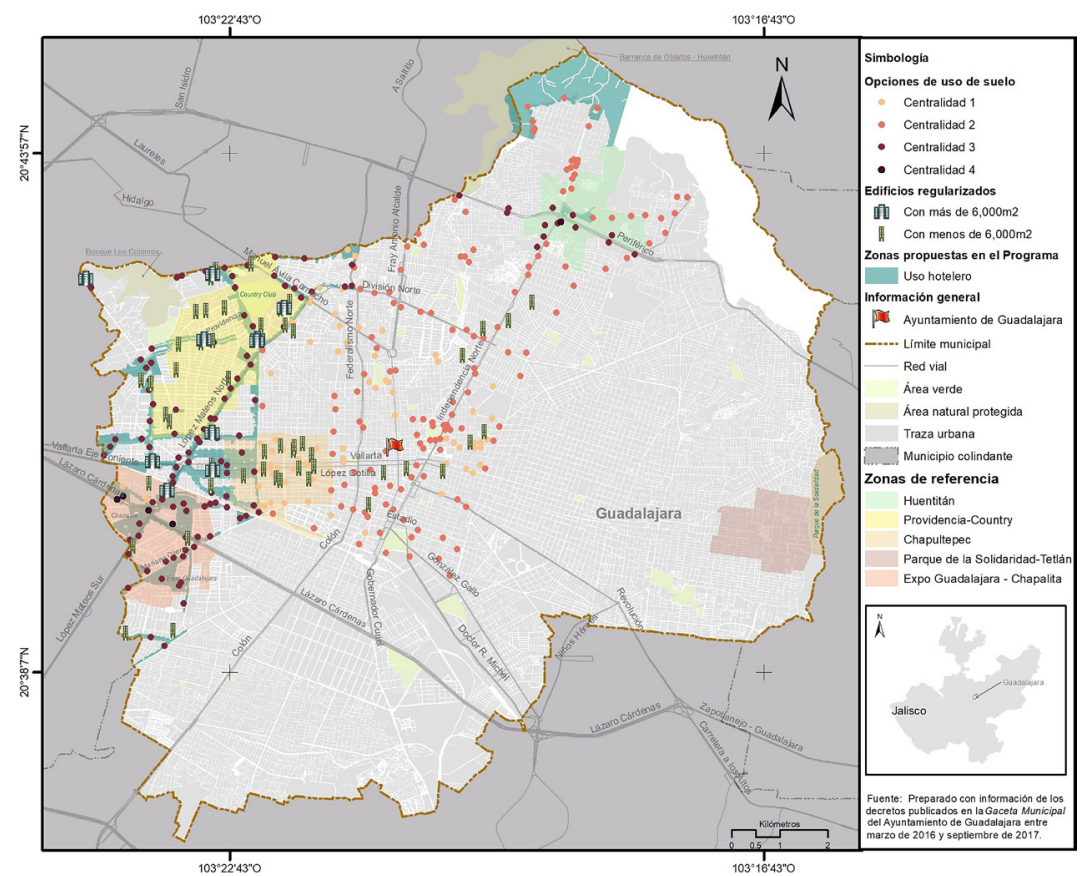

Fuente: elaboración propia con datos de los decretos publicados en la Gaceta municipal (Ayuntamiento de Guadalajara, 2016-2017). 
En el programa CIMAU, el gobierno municipal simplemente toma como dada una zonificación que fue construida sin una política seria de ordenamiento del proceso de densificación de la ciudad central.

Dicha zonificación incorporaba zonas receptoras y transmisoras de derechos de desarrollo, pero en el diseño del programa se tomó la decisión de distribuir oportunidades de formación de economías de aglomeración por corredores viales en vez de tomar en forma integral polígonos de la ciudad. ${ }^{1}$

Con esa decisión, el Programa CIMAU desecha la posibilidad de aprovechar el potencial de las economías de aglomeración, asociadas a la existencia de buena accesibilidad y amenidades que contribuyen a procesos de densificación apreciados por el mercado inmobiliario y por los flujos de turistas que buscan sitios urbanos para construir experiencias memorables. La zonificación usada desaprovecha también la posibilidad de enfocar el debate público en la tarea de negociar los conflictos derivados de la transición de polígonos urbanos específicos, donde se libran actualmente las batallas relevantes para el posicionamiento de la ciudad en la economía internacional. El programa se limita a sancionar con tarifas modestas los excesos cometidos por los desarrolladores, usando como referencia planes que de origen tenían problemas serios para aprovechar la dinámica del mercado inmobiliario.

\section{Gráfica 2}

\section{Principales edificaciones que participan en el programa CIMAU según metros cuadrados regularizados con la tarifa $\mathrm{T} 1$}

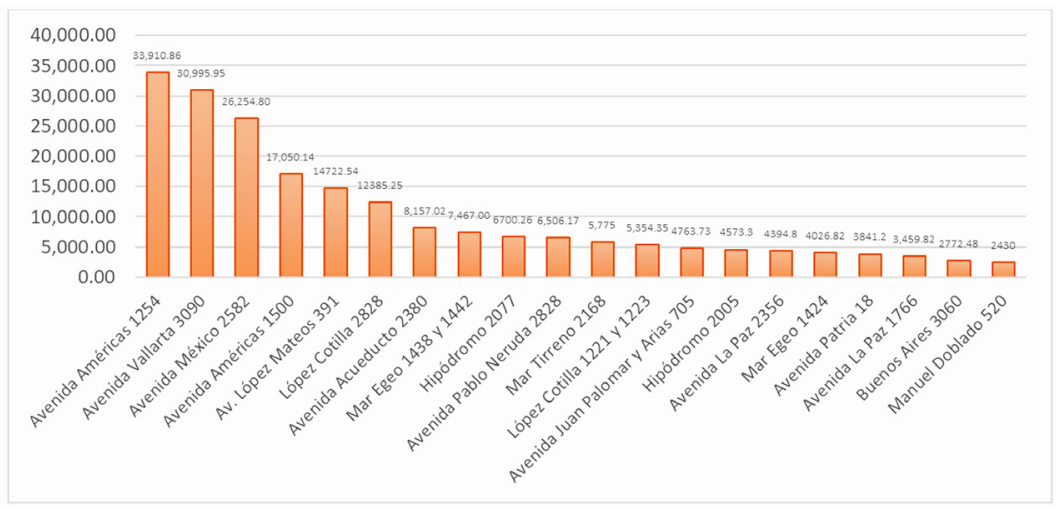

Fuente: elaboración propia con datos de los decretos publicados en la Gaceta municipal (Ayuntamiento de Guadalajara, 2016-2017).

${ }^{1}$ Para construir el mapa de la figura 2 se usó información de las zonificaciones propuestas en 2015 y 2017. La regulación de usos corresponde a 2015 y los polígonos corresponden a la propuesta de planes parciales de 2017. 
El programa CIMAU constituye de facto una actualización ad hoc y deficiente de planes parciales que no fueron implementados. Con ello, ofrece oportunidades de acumulación a desarrolladores e inversionistas que encontraron las rendijas legales y las relaciones personales que les permitieron concluir edificaciones que no cumplían, de entrada, con lo establecido en los planes parciales de desarrollo urbano vigentes.

\subsection{Evaluación con el criterio de eficiencia de captura de plusvalias}

La eficiencia de captura de plusvalías hace referencia a dos dimensiones analíticas igualmente importantes. Por una parte, se refiere al criterio de bienestar social, en este caso, medido por el grado en el que las estimaciones de los impactos y las compensaciones determinadas contribuyen efectivamente a mejorar el bienestar de la población en la ciudad y no sólo en los distritos mejor favorecidos y, segundo, se refiere al grado en el que las tarifas cobradas se aproximan a las plusvalías efectivamente obtenidas por los desarrolladores que participan en el programa, el cual se puede medir usando como referente aproximado la dispersión y la distancia de las cuotas cobradas por los distintos rubros con los valores de mercado del suelo en Guadalajara.

En esta evaluación, se consultaron todos los decretos referentes a la autorización del procedimiento de compensación e indemnización para las edificaciones que fueron dictaminadas entre el 2 de marzo de 2016 y el 19 de septiembre de 2017. La revisión dio como resultado un total de 60 decretos que autorizan al gobierno municipal para establecer un convenio con los propietarios de los edificios. Esta evaluación identifica dos grandes sesgos:

1. Castiga poco el exceso de edificación. Si bien el programa está diseñado para todo tipo de propietario que hubiera edificado por encima de lo permitido en el CUS de los planes parciales vigentes, las primeras 60 edificaciones regularizadas sugieren que el programa ha sido aprovechado principalmente por los desarrolladores que cometieron mayores excesos en las zonas de la ciudad con mayor plusvalía. Como se puede ver en la gráfica 2 , sólo una docena de edificaciones se excedieron en 5000 metros cuadrados o más, pero de ellas sobresalen cuatro desarrollos con cantidades superiores a los 15,000 metros cuadrados de construcción regularizados.

2. No hace buenas estimaciones de la compensación. El reglamento establece una compleja estructura de implementación y un procedimiento que involucra la opinión de varias dependencias para estimar las compensaciones y medidas de mitigación contem- 
pladas para cada caso. Sin embargo, el valor de las compensaciones fue estimado tomando como base solamente los parámetros de COS pero principalmente del CUS, como se señala en la figura 1.

El cuadro 2 presenta, en forma agregada, los avances del programa entre marzo de 2016 y septiembre de 2017 . El programa ha permitido al gobierno municipal capturar un total de 182,876,383.49 pesos equivalentes a aproximadamente 10 millones de dólares (tipo de cambio de 18.20 pesos por dólar). De éstos, $66.04 \%$ se recuperaron usando una tarifa que prácticamente no introduce diferenciación alguna en la plusvalía, pues el rango de precios por metro cuadrado estuvo entre 244 (un caso), y 733 (otro caso), pero la mayoría pagaron entre 400 y 500 pesos por metro usando la tarifa $\mathrm{T} 1$, lo cual contrasta con los precios detectados en el mercado que alcanzan, en la zona de Providencia, hasta 25,000 pesos por metro cuadrado. El $32.51 \%$ de los recursos recaudados provienen de T2 y, por lo tanto, usan como referente el valor catastral de los terrenos, que si bien se aproximan mejor a la plusvalía, no resuelve del todo el problema de subestimación de la misma. Esto se debe a que las brechas de valor catastral/valor de mercado favorecen a propietarios en los predios de mayor plusvalía y dinamismo económico. Hay un $1.46 \%$ de recursos obtenidos de un pequeño número de predios a los que se les cobró la tarifa T1 en vez de la tarifa T2.

\section{Cuadro 2 \\ Metros regularizados y cantidades recuperadas según tarifa (2016-2017)}

\begin{tabular}{lccc}
\hline & $\begin{array}{c}\text { Metros cuadrados } \\
\text { regularizados según } \\
\text { tarifa }\end{array}$ & $\begin{array}{c}\text { Cantidad recuperada } \\
\text { por mecanismo de } \\
\text { compensación }\end{array}$ & $\begin{array}{c}\text { Porcentaje de } \\
\text { compensaciones } \\
\text { recuperadas según tarifa }\end{array}$ \\
\hline Totales & $251,465.34$ & $182,876,383.49$ & \\
Total (ICUS T1) & $237,165.54$ & $120,764,805.34$ & 66.04 \\
Excedido (T2-1) & $5,570.31$ & $2,660,981.25$ & 1.46 \\
Excedido (T2-2) & 8729.50 & $59,450,596.90$ & 32.51 \\
\hline
\end{tabular}

Fuente: elaboración propia con datos de los decretos publicados en la Gaceta municipal (Ayuntamiento de Guadalajara, 2016-2017).

La información revisada revela que el procedimiento contemplado tiene varias deficiencias como instrumento de captura de plusvalías y, por lo tanto, pocas posibilidades de ser utilizado para apoyar grandes objetivos de desarrollo urbano en la ciudad. 
a) Usa indicadores muy vagos para capturar la plusvalía generada por el desarrollo urbano. Dado que T1 se estima con un valor fijo por zonas establecido en la Ley de Ingresos, hay una brecha entre el valor asignado en la Ley de Ingresos y el valor de mercado por metro cuadrado. Por lo tanto, el procedimiento beneficia a los propietarios con predios con un valor en el mercado por metro cuadrado más alejado del valor reconocido por la Ley de Ingresos, lo que tiende a ocurrir en las zonas más caras y más dinámicas.

b) La tarifa T2 se cobra a muy pocos predios, lo que induce sesgos que favorecen a grandes desarrolladores. Al tomar como base el valor catastral, esta tarifa se aproxima más que la tarifa $\mathrm{T} 1$ a las variaciones en el valor de mercado y, por lo tanto, a las plusvalías generadas por el desarrollo urbano. Aun así, mantiene un sesgo regresivo que favorece a los que más tienen. Si bien desde 1999 hay el mandato constitucional de que los municipios actualicen sus tablas de valores catastrales a valor de mercado, en la práctica eso no sucede. De esta manera, al usar ese referente para estimar el excedente construido por encima del ICOS, se beneficia a los desarrolladores cuyas propiedades presentan las brechas más grandes. Más aún, al revisar los casos, se encontró que en algunos de ellos, no se utilizó el valor catastral sino el mismo valor usado en T1.

Los sesgos anteriores permiten afirmar que el programa tiene una orientación regresiva. Como se muestra en el cuadro 3, si bien el programa fue planteado como un programa abierto a la participación de las personas físicas o morales que tuvieran edificios con construcción iniciada hasta antes de octubre de 2015 con densidades de utilización del suelo superiores a lo contemplado en los planes vigentes aprobados en 2003, en la práctica, el programa ha servido a los intereses de grandes desarrolladores responsables de proyectos ambiciosos ubicados en zonas de la ciudad con algunas de las plusvalías más altas. En el cuadro 3 se muestran los 12 proyectos con más metros regularizados con la tarifa T1. Para ilustrar los sesgos del programa, vale la pena destacar lo siguiente:

- Todos los promotores, son empresas con experiencia en desarrollar grandes proyectos de uso mixto y un banco.

- En tres de cada cuatro propiedades de esta lista, se cobró únicamente la tarifa $\mathrm{T} 1$ en una de ellas a cargo de Inmobiliaria Ve-Lejos S. A. de C. V., se cobró una tarifa adicional, pero con el mismo valor por metro cuadrado que T1, y sólo en dos de ellas se recurrió al cobro de una tarifa de excedencia utilizando la tarifa T2 con base en valor catastral (Cititower GDL, S. A. de C. V., y Banco del 


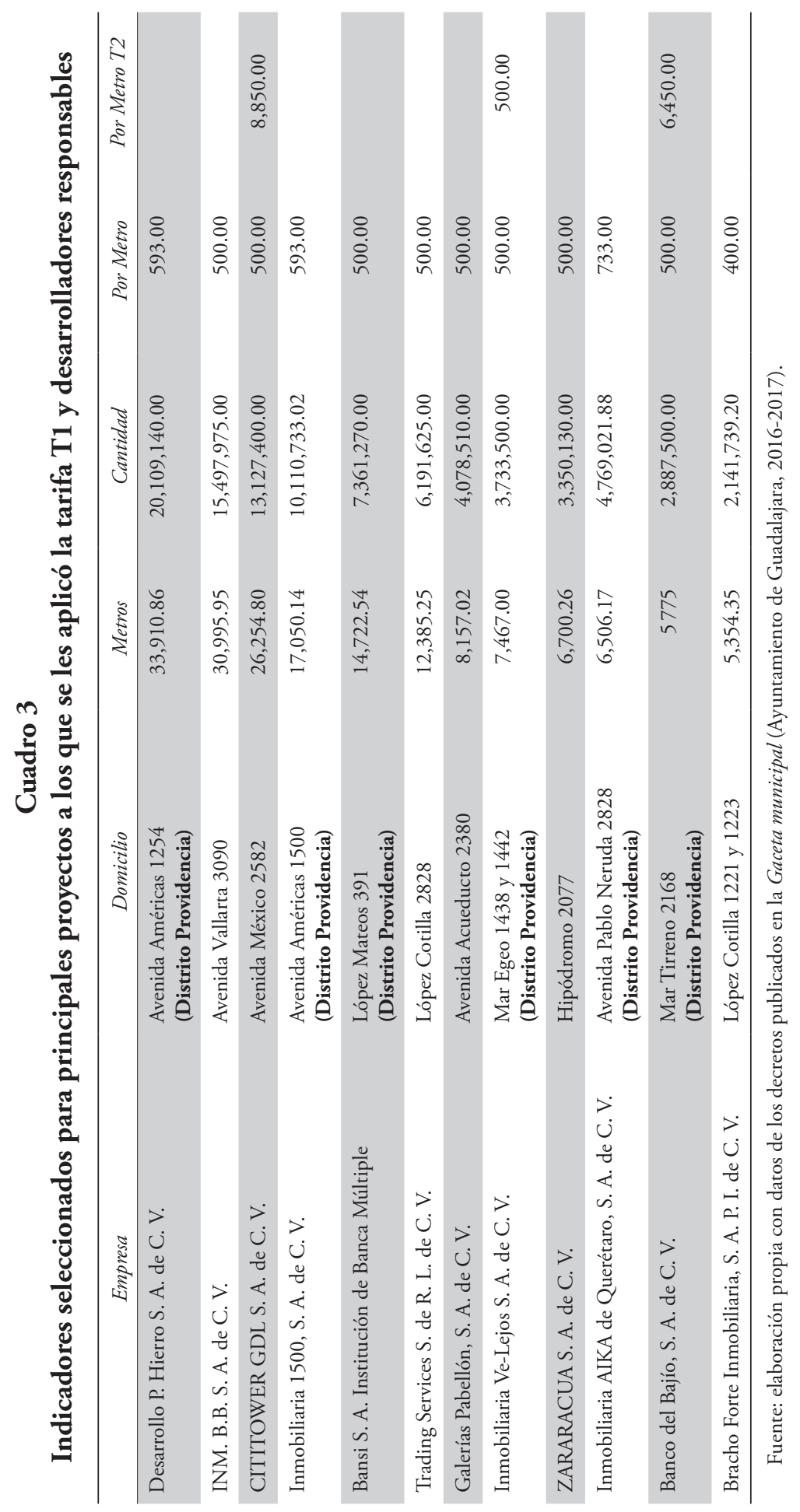


Bajío, S. A. de C. V.). El caso de Cititower GDL destaca porque además se ordenó demoler algunos metros de su construcción, dados los excesos cometidos por el desarrollador.

- La mitad de los proyectos se construyeron en el polígono de Providencia, que se ha constituido en los últimos años como uno de los principales distritos urbanos gastronómicos de la ciudad. Ahí se está formando un paisaje urbano con marcada influencia anglosajona, similar a lo que está ocurriendo en otras ciudades del mundo.

- En el cuadro 4 se muestran algunos valores agregados que dan cuenta del grado en el que los grandes desarrolladores han aprovechado el programa. El 81\% de los metros regularizados en los edificios más grandes fue aprobado en 2016, lo cual sugiere que los desarrolladores de ese tipo de edificios aprovecharon de forma temprana su inclusión como población objetivo merecedora de los beneficios del programa. Los 12 edificios con más metros regularizados en el periodo estudiado representan $74.91 \%$ de los metros regularizados y $77.31 \%$ de los recursos cobrados. La polarización en el aprovechamiento del programa se observa más clara cuando se considera que los cinco edificios más grandes representan $51.83 \%$ del total de metros regularizados y $54.82 \%$ de los recursos recuperados por el municipio.

\section{Cuadro 4}

\section{Valores agregados y relativos para indicadores seleccionados para los 12 edificios con más metros regularizados (programa CIMAU)}

\begin{tabular}{lcc}
\hline \multicolumn{1}{c}{ Indicadores seleccionados } & Cantidad & $\begin{array}{c}\text { Valores relativos } \\
\text { (\%) }\end{array}$ \\
\hline $\begin{array}{l}\text { Metros regularizados en el programa } \\
\text { Cantidad recaudada por T1 en el programa } \\
\text { (pesos) }\end{array}$ & $251,465.34$ & \\
Regularizados por decreto publicado en 2016 & $\$ 120^{\prime} 764,805.34$ & \\
Regularizados por decreto publicado en 2017 & 9 & $81.00($ a $)$ \\
Metros regularizados & $175,279.34$ & $19.00($ a $)$ \\
Cantidad recuperada (pesos) & $\$ 93^{\prime} 358,544.91(b)$ & $77.31(b)$ \\
Metros de cinco más grandes & $122,934.29$ & $51.83(b)$ \\
Cantidad de cinco más grandes (pesos) & $\$ 38^{\prime} 736,108.02$ & $54.82(b)$ \\
\hline
\end{tabular}

Notas: (a) Metros con respecto a los 12 edificios con más metros regularizados.

(b) Con respecto al total de avances del programa 3-3-2016 al 19-9-2017.

Fuente: elaboración propia con datos de los decretos publicados en la Gaceta municipal (Ayuntamiento de Guadalajara, 2016-2017). 
La gráfica 3 presenta la relación entre porcentaje de metros regularizados y porcentaje de recursos recuperados. En ella se puede observar que, en el caso de los 10 edificios más grandes, la cantidad pagada es proporcionalmente mayor a los metros regularizados, ello se debe a que en esos grupos hay edificios cuyas excedencias fueron cobradas a valor catastral del terreno. El diseño de medidas de mitigación consideradas en los decretos de regularización con los que se autoriza al gobierno municipal a negociar un acuerdo con los interesados en participar en el programa, no cuenta con un procedimiento claro de identificación, caracterización y valoración de impactos urbanos que incorpore las mejores prácticas disponibles a nivel internacional en materia de evaluación de impacto ambiental y evaluación de impacto social de proyectos.

\section{Gráfica 3 \\ Porcentaje de metros regularizados y cantidad pagada por rango de tamaño de edificios participantes en el programa CIMAU (2016-2017)}

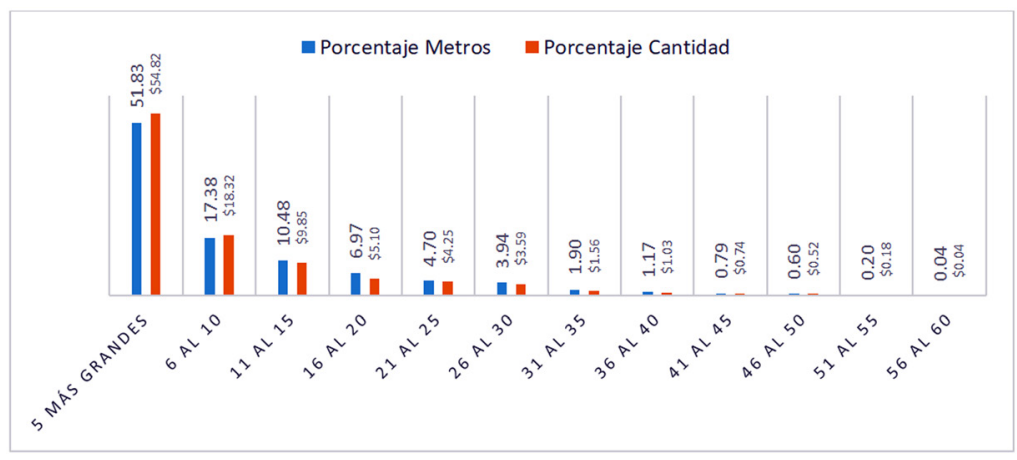

Fuente: elaboración propia con datos de los decretos publicados en la Gaceta municipal del (Ayuntamiento de Guadalajara, 2016-2017).

En este artículo no se hace un análisis detallado de todas las medidas contempladas en cada uno de los proyectos, y su distribución en el territorio. Para mostrar las inconsistencias de esta parte del proceso de implementación del programa basta decir que, en todos los casos, el menú de opciones abarca principalmente los siguientes tipos de acciones: 1 . Proyecto de gestión de residuos mediante la instalación de uno o más puntos limpios con contenedores clasificados; 2. Proyecto de plan de manejo de arbolado urbano que puede abarcar plan de saneamiento de una cuota de árboles en un polígono cercano al edificio; 3 . Rehabilitación y ampliación de bibliotecas municipales, que puede ser pago en especie o aportación económica; 4. Programa de cruceros seguros; 5 . Rehabilitación de unidades 
deportivas; 6. Rehabilitación y ampliación del patrimonio escultórico y 6. Donación de terrenos. La gráfica 4 muestra que la mayor cantidad de recursos fue asignada a terrenos obtenidos vía donación para obras y proyectos ubicados cerca del desarrollo City Tower. Los otros dos programas que más recibieron recursos son el de rehabilitación y ampliación del patrimonio escultórico, y el de adquisición de vehículos para protección civil, mismo que fue introducido en 2017.

\section{Gráfica 4}

\section{Distribución de inversiones de compensación y mitigación según programa CIMAU (pesos)}

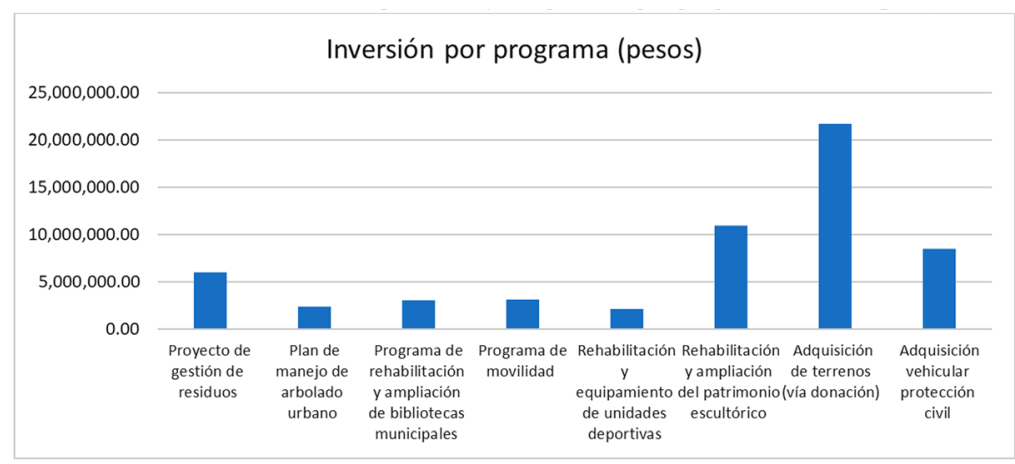

Fuente: elaboración propia con datos de los decretos publicados en la Gaceta municipal (Ayuntamiento de Guadalajara, 2016-2017).

Al revisar los decretos publicados, no queda claro por qué en algunos casos se especifican cantidades para acciones y en otros no, pero sobre todo no queda claro cuál es el criterio usado para decidir si se invierte más en ampliación del capital escultórico o en el inventario de árboles de una zona determinada. Más aún, mientras que para acciones como el programa de manejo de arbolado se establece, pero no en todos los casos, las zonas donde se aplica, para otras acciones no se contempla dicha ubicación. En general, cuando se contemplan las zonas que reciben las medidas de compensación o mitigación, suelen ser zonas muy próximas al sitio donde se construyó el edificio, lo cual, dada su distribución y su magnitud, tiende a favorecer de nuevo a las zonas de mayor plusvalía, minimizando el impacto en la reducción de las inequidades urbanas existentes en la zona metropolitana. 


\section{Análisis de los resultados}

Los resultados del programa CIMAU, derivados de la evaluación anterior, sugieren que el gobierno local de Guadalajara ha optado por un instrumento de captura de plusvalías que tiene potencial para generar recursos con el fin de financiar del desarrollo urbano y la corrección de sus externalidades negativas. Sin embargo, ha utilizado este instrumento en forma insuficiente, lo cual, en términos generales, disminuye su eficiencia en la captura de plusvalías y le resta efectividad para disminuir las desigualdades sociales. De conformidad con los criterios de evaluación, los resultados obtenidos sugieren la existencia de los siguientes aspectos positivos y negativos.

\subsection{Aspectos positivos y negativos conforme al criterio de centralidad}

La regularización de edificios de gran altura establece un nuevo referente para una mayor densidad futura en las zonas con mayor demanda de suelo que tienen una ubicación central en el contexto de la zona metropolitana. Al regularizar edificaciones de mayor altura, el programa facilita la aparición de desarrollos de uso mixto y la diversificación de servicios de hospedaje como ha ocurrido en los nuevos desarrollos cercanos a la Glorieta Colón, en la confluencia de avenida López Mateos y avenida Américas. Al impulsar la opción de consolidación de nuevas centralidades, el programa contribuye al ordenamiento general metropolitano y reconoce el papel del mercado como impulsor de economías de aglomeración, reflejados en la conformación de distritos urbanos gastronómico-turísticos que pueden aportar a la competitividad de la ciudad.

El programa CIMAU ayuda a lograr usos más intensos del suelo en ubicaciones centrales, independientemente del uso dominante de los mismos y permite la consolidación de distritos con usos mixtos, reduciendo con ello la segregación de usos de suelo observada en la expansión metropolitana de las últimas décadas. Las aglomeraciones urbanas que se benefician con el programa, eventualmente pueden resultar en cambios en el trazado del transporte colectivo y mitigar el congestionamiento vial. Asimismo, amplían las opciones que encuentran los turistas para construir sus propias experiencias.

Sin embargo, también hay aspectos negativos: el apoyo dado por el programa a la formación de distritos de negocios y turismo es inconsistente con los principios de la teoría de la renta y las nuevas corrientes de economía urbana que han identificado a la formación de distritos de negocios creativos y al turismo basado en experiencias como dos impulsores del 
desarrollo urbano. El programa beneficia a 317 zonas con regulación propicia a la conformación de aglomeraciones de uso mixto, pero no corrige la falla persistente de los planes urbanos de la ciudad que ignoran las tendencias de crecimiento polarizado del mercado inmobiliario.

Los principales edificios regularizados se ubican relativamente alejados de las rutas de transporte masivo del tren ligero, incluida la que está en construcción, por lo que, en el corto plazo, la regularización contribuye al congestionamiento vial existente. El programa considera usos hoteleros casi exclusivamente en el poniente de la ciudad, lo cual restringe la posibilidad de que ese tipo de usos apoyen la consolidación de subcentros de negocios y turismo en zonas de la ciudad con aglomeraciones e identidades barriales que agregan diversidad económica y social a la ciudad.

El diseño tiene un claro sesgo hacia la densificación en el poniente de la ciudad, y de manera más específica en el distrito 2 Providencia, que abarca las zonas más ricas de la ciudad y es considerada por los desarrolladores inmobiliarios como la joya de la corona en la carrera de la especulación urbana en zonas centrales generadas por el proceso de crecimiento metropolitano. En ese distrito se ubica la mayoría de los grandes desarrollos regularizados, y algunos de ellos son parte de la aglomeración de oficinas, hoteles, viviendas de lujo y restaurantes que se está formando en las inmediaciones de la Glorieta Colón, en la confluencia de la avenida Américas y la avenida López Mateos, zona que abarca principalmente a las colonias Providencia y Country.

Las tarifas usadas en el programa son muy bajas y los fondos recuperados apenas alcanzan para soluciones remediales a problemas locales que se agudizan durante la etapa de construcción de los nuevos proyectos o para financiar proyectos insignificantes en el paisaje urbano que poco aportan al capital cultural de la ciudad, como la escultura de la pluma, instalada en el camellón de la avenida Américas, en un crucero donde pasa virtualmente desapercibida.

\subsection{Aspectos positivos y negativos conforme al criterio de eficiencia}

Respecto al criterio de eficiencia en la recuperación de plusvalía cabe resaltar que el programa no fue diseñado explícitamente con esa racionalidad, pero los instrumentos usados justifican su consideración como un programa con el potencial de disminuir la desigualdad social.

La distinción entre tarifa 1 (T1) para cuotas fijas por metro establecidas en la Ley de ingresos y la tarifa 2 (T2) para excedencias cobradas conforme al valor catastral permite sancionar, en forma diferenciada, los grados de exceso cometidos por los desarrolladores. Al recuperar plusvalías ex post mediante tarifas por derechos de construcción, el programa mitiga el pro- 
blema de apropiación privada de dichas plusvalías y crea un fondo pequeño para financiar el proceso de desarrollo urbano en la ciudad central.

La aceptación del programa por parte de varios involucrados abre la puerta a programas más ambiciosos de recuperación de plusvalía en la medida que se socializa la idea de recuperar plusvalías y su aceptación como un activo de la colectividad, no de los propietarios de los predios, cuyo valor aumenta con el proceso de desarrollo urbano. La ciudad, efectivamente, ha logrado recursos que le han permitido atender problemas urgentes de seguridad vial, atención al arbolado y manejo de residuos sólidos en zonas de la ciudad que ya presentan problemas importantes en ese sentido.

El programa ha permitido canalizar recursos a equipamientos de bibliotecas, lo cual genera beneficios para la sociedad en general. Mención especial merece el uso de recursos para mantenimiento y ampliación del patrimonio escultórico de la ciudad, pues con ello se enriquece el paisaje urbano y el capital cultural de la ciudad en su conjunto, un tema que se encuentra prácticamente olvidado en las decisiones de gasto público en los tres órdenes de gobierno.

Sin embargo, el programa tiene varios aspectos negativos. En primer lugar, muestra de origen un sesgo socio-espacial consistente con la tendencia de segregación social oriente-poniente que ha caracterizado a la ciudad desde su fundación. Las tarifas usadas para estimar el monto de las compensaciones tienen un claro sesgo favorecedor hacia los desarrolladores más grandes que están aprovechando a mayor escala las plusvalías del desarrollo urbano en el poniente de la ciudad. La distinción de tarifas cobradas no es suficiente para capturar el grado en el que los desarrolladores se benefician de la plusvalía generada en las nuevas aglomeraciones de negocios y turismo. Los empresarios asociados al sector turismo y servicios son los que más se favorecen con este sesgo. En el diseño del programa se contempla facilitar la regularización de construcción de establecimientos de hospedaje sobre todo en el distrito Providencia, con algunas zonas ubicadas en Huentitán para turismo ecológico y algunas excepciones ubicadas en otras partes de la ciudad. Las acciones de desarrollo del capital escultórico han sido fuertemente criticadas porque algunas obras, de acuerdo con los críticos, tienen un dudoso valor artístico y una mala ubicación.

El programa no es eficiente en la captura de plusvalías porque las tarifas de compensación no capturan adecuadamente la distribución territorial de la plusvalía del desarrollo urbano de la ciudad central en un contexto metropolitano. Este hecho le resta legitimidad política al programa, porque su aplicación se puede presentar con facilidad como un paquete de favores políticos a grandes desarrolladores. 
La opinión anterior, se fortalece cuando se observa que hay una clara concentración de los beneficios del programa en unos cuantos desarrolladores de grandes proyectos de uso mixto, ubicados en las principales zonas de negocios del poniente de la ciudad. La concentración de las medidas de mitigación en los entornos inmediatos y los sesgos hacia inversiones no necesariamente consensadas con las poblaciones afectadas. En este rubro, destacan obras de aseo público, acciones de pintura y brocha para resolver problemas de congestionamiento, seguridad vial, y financiamiento de un programa para el cuidado y la ampliación del capital escultórico de la ciudad.

\section{Conclusiones}

El programa CIMAU de Guadalajara, aprobado en marzo de 2016, es un instrumento del gobierno local que busca compensaciones por violaciones a la zonificación, pero influye en la conformación de distritos de negocios y de turismo. El programa CIMAU ilustra como el sector público termina por hacerse cargo de los costos de urbanización y genera plusvalías apropiables por los inversionistas privados lo cual genera un sesgo en la distribución de beneficios de la ciudad que difícilmente pueden ser corregidos con un programa de este tipo. Su implementación presenta deficiencias como impulsor de aglomeraciones y en su eficiencia recaudatoria y distributiva, por lo que contribuye más a facilitar una forma desigual de desarrollo urbano que a alcanzar justicia social urbana. El análisis realizado revela que el programa tiene aspectos positivos y negativos en los criterios de aglomeración y de eficiencia.

El programa contribuye a identificar las dificultades para regenerar centros urbanos e inducir una mayor densidad de ocupación del suelo. Éste podría ampliar los beneficios en el criterio de centralidad, si establece valores diferenciados para edificaciones que corresponden a las regulaciones de uso de suelo que, a su vez, capturan mejor la dinámica del mercado inmobiliario. El programa podría ampliarse para aprovechar las ventajas de localización asociadas a la construcción de la línea 3 del tren ligero e impulsar acciones urbanísticas de densificación, en las inmediaciones de las estaciones.

El programa CIMAU podría mejorar su eficiencia y contribuir a reducir la desigualdad social, si contempla tarifas más cercanas a las plusvalías efectivamente generadas. Eso permitiría al gobierno local incrementar los recursos utilizados en las áreas cercanas a las edificaciones, y usar parte de ellos para generar beneficios en las partes menos favorecidas de la ciudad. Tomando en cuenta los resultados de esta evaluación, es reco- 
mendable hacer modificaciones al programa para facilitar la conformación de centralidades en el territorio del municipio y para maximizar su impacto en temas como movilidad y justicia social. Para ello, es necesario revisar los criterios y procedimientos usados en la identificación, caracterización y valoración de impactos, así como en el diseño de las medidas de mitigación.

\section{Fuentes consutadas}

Aitchison, Cara, Nicola MacLeod y Stephen Shaw (2000), Leisure and tourism landscapes: social and cultural geographies, Routledge, Nueva York, Estados Unidos de América.

Alonso, William (1964), Location and Land Use. Toward a General Theory of Land Rent, Harvard University Press, Cambridge, Estados Unidos de América.

Alonso, William (1960), "A theory of the urban land market", Papers in Regional Science, 6 (1), Regional Science Association, Filadelfia, Estados Unidos de América, pp. 149-157.

Ayuntamiento de Guadalajara (2016-2017), Gaceta municipal, varios números del 3 de marzo de 2016 al 15 de agosto de 2017, Gobierno de Guadalajara, Guadalajara, México, <http://bit. ly/2vK5DLo>, 3 de junio de 2017.

Ayuntamiento de Guadalajara (2016), "Reforma al reglamento de gestión del desarrollo urbano para el municipio de Guadalajara y se aprueban las disposiciones administrativas de aplicación general que regulan los mecanismos de compensación, indemnización y mitigación por acciones urbanísticas en el municipio de Guadalajara”, Gaceta municipal, tomo II, 2 de marzo, Gobierno de Guadalajara, Guadalajara, México, <http://bit.ly/2xz8pQf>, 3 de junio de 2017.

Blanco, Andrés, Nancy Moreno, David Vetter y Marcia Vetter (2016), El potencial de la captura de plusvalías para la financiación de proyectos urbanos: consideraciones metodológicas y casos prácticos, Banco Interamericano de Desarrollo, Washington, Estados Unidos de América, <http://bit.ly/2gc9D0o>, 23 de junio de 2017. 
Brueckner, Jan (1997), "Infrastructure financing and urban development: the economics of impact fees", Journal of Public Economics, 66 (3), Elsevier, Amsterdam, Holanda, pp. 383-407.

Christensen, Finn Kjaer (2011), "When property value changes during urban development: Model and factors", tesis de doctorado, Institut for Samfundsudvikling og Planlaegning, Aalborg Universitet, Aalborg, Dinamarca.

Cruz-Muñoz, Fermín Alí (2016), "Influencia de la política de zonificación urbana en la localización industrial de la Ciudad de México, 1986-2014", Economía, Sociedad y Territorio, XVI (51), El Colegio Mexiquense, Toluca, México, pp. 339-374.

Cuenya, Beatriz (2016), "La política urbana frente a la mercantilización y elitización de la ciudad: algunas reflexiones y referencias a la situación argentina", Cuaderno Urbano. Espacio, Cultura, Sociedad, 21 (21), Universidad Nacional del Nordeste, Corrientes, Argentina, pp. 167-194.

Fainstein, Susan (2012), "Land value capture and justice", en Gregory K. Ingram y Yu-Hung Hong (eds.), Value Capture and Land Policies, Lincoln Institute of Land Policy, Cambridge, Estados Unidos de América, pp. 21-40.

Fischer, Lauren y Elliott Sclar (2016), "Value capture: Why we may be disappointed”, en Elliott D. Sclar, Måns Lönnroth y Christian Wolmar (eds.), Improving urban access: new approaches to funding transport investment, Routledge, Nueva York, Estados Unidos de América, pp. 120-145.

Government of India (2017), Value capture finance policy framework, Ministry of Urban Development, Nueva Delhi, India, <http:// www.smartcities.gov.in/upload/5901982d9e461VCFPolicyFram eworkFINAL.pdf>, 21 de julio de 2017.

Haila, Anne (2015), Urban land rent: singapore as a property state, John Wiley and Sons Ltd, Chichester, Reino Unido.

Huffman, Forrest, Arthur Nelson, Marc Smith y Michael Stegman (1988), "Who bears the burden of development impact fees?", Journal of 
the American Planning Association, 54 (1), American Planning Association, Washington, Estados Unidos de América, pp. 49-55.

Hui, Eddie Chi-Man, Vivian Sze-Mun Ho y David Kim-Hin Ho (2004), "Land value capture mechanisms in Hong Kong and Singapore: A comparative analysis", Journal of Property Investment and Finance, 22 (1), Emerald Publishing, Bingley, West Yorkshire, Reino Unido, pp. 76-100.

Imeplan (Instituto Metropolitano de Planeación) (2016), "Plan de Ordenamiento Territorial Metropolitano del AMG”, Instituto Metropolitano de Planeación, Área Metropolitana de Guadalajara, Guadalajara, México, <http://bit.ly/2eIxV1Q>, 4 de junio de 2017.

IIEG (Instituto de Información Estadística y Geográfica del Estado de Jalisco) (2015), "Población total por entidad, municipios y edad desplegada según sexo, 2015”, IIEG, Jalisco, México, <http://bit. ly/2iDBs2s>, 2 de junio de 2017.

Jeong, Moon-Gi (2006), "Local choices for development impact fees", Urban Affairs Review, 41 (3), Sage Publications, Thousand Oaks, Estados Unidos de América, pp. 338-357.

Jiménez-Martínez, Alfonso (2017), "Las universidades y el turismo: reflexiones sobre la investigación turística en México", Dimensiones Turísticas, 1 (1), Academia Mexicana de Investigación Turística, Mazatlán, Sinaloa, México, pp. 141-153.

López-Morales, Ernesto y Daniel Meza-Corvalán (2015), "Regulaciones públicas y explotación de renta del suelo: el boom inmobiliario de Nuñoa, Santiago, 2000-2010", Economía, Sociedad y Territorio, XV (48), El Colegio Mexiquense, Toluca, México, pp. 301-332.

McIntosh, Alison (1999), "Into the tourist's mind: Understanding the value of the heritage experience", Journal of Travel \& Tourism Marketing, 8 (1), Taylor and Francis, Oxford, Reino Unido, pp. 41-64.

Monterrubio, Juan Carlos (2017), "Necesidades de la investigación turística en México. Reflexiones en el marco de la investigación 
internacional", Dimensiones Turísticas, 1 (1), Academia Mexicana de Investigación Turística, Mazatlán, Sinaloa, México, pp. 29-50.

Murphy, Peter y Ann Murphy (2004), Strategic Management for Tourism Communities, Bridging the Gaps, Channel View Publications, Clevendon, Reino Unido.

Neville, Joshua, Malcolm Campbell, Ria Dionisio y Simon Kingham (2015), Land value capture to fund transport investment in cities: International implementation case studies and the lessons that can be learned from these, The Building Research Association of New Zealand, Wellington, Nueva Zelanda.

Nilsson, Carolina (2011), "Valuation of development rights. Current practice and limitations", tesis de maestría, Department of Real Estate Construction and Management, The Royal Institution of Technology, Estocolmo, Suecia, <http://bit.ly/2xML1zw>, 12 de julio de 2017.

OCDE (Organización para la Cooperación y el Desarrollo Económico) (2017), "The governance of land use in the Netherlands: The case of Amsterdam", OCDE Publishing, París, Francia, <http://bit. ly/2eIOR8k>, 12 de julio de 2017.

Parsons, George Russell y Joëlle Noailly (2004), "A value capture property tax for financing beach nourishment projects: An application to Delaware's ocean beaches", Ocean \& Coastal Management, núm. 47, Elsevier, Amsterdam, Holanda, pp. 49-61.

Peiró-Signes, Angel, Maria-del-Val Sagarra-Oña, Luis Miret-Pastor y Rohit Verma (2014), "The effect of tourism clusters on U.S. hotel performance", Cornell Hospitality Quarterly, núm. 55, Sage Publications, Thousand Oaks, Estados Unidos de América, pp. 1-13.

Peterson, George (2008), Unlocking land values to finance urban infrastructure, The World Bank, Washington, Estados Unidos de América.

Sandroni, Paulo (2016), "La captura de plusvalías urbanas en Brasil: el uso de los CEPACs y la otorga onerosa del derecho de construir en la ciudad de São Paulo (1986-2013)", en Andrés Blanco, Vicente Fretes y Andrés Muñoz (eds.), Expandiendo el uso de la 
valorización del suelo: la captura de plusvalías en América Latina y el Caribe, Banco Interamericano de Desarrollo, Washington, Estados Unidos de América, pp. 47-67.

Sandroni, Paulo (2011), "Experiencia reciente de recuperación de plusvalías en São Paulo, Brasil”, Land Lines, 23 (3), Lincoln Land Institute, Cambridge, Estados Unidos de América, pp. 16-21.

Shoval, Noam (2006), "The geography of hotels in cities: An empirical validation of a forgotten model", Tourism Geographies, 8 (1), Taylor and Francis, Oxford, Reino Unido, pp. 56-75.

Singell, Larry y Jane Lillydahl (1990), "An empirical examination of the effect of impact fees on the housing markets", Land Economics, 66 (1), University of Wisconsin Press, Madison, Estados Unidos de América, pp. 82-92.

Skaburskis, Andrejs y Mohammad Qadeer (1992), "An empirical estimation of the price effects of development impact fees", Urban Studies, 29 (5), Sage Publications, Thousand Oaks, Estados Unidos de América, pp. 653-667.

Smolka, Martim (2013), Implementación de la recuperación de plusvalias en América Latina: politicas e instrumentos para el desarrollo urbano, Lincoln Institute of Land Policy, Cambridge, Estados Unidos de América.

Smolka, Martim y David Amborski (2003), "Recuperación de plusvalías para el desarrollo urbano: una comparación inter-americana", Eure-Revista Latinoamericana de Estudios Urbanos Regionales, 29 (88), Pontificia Universidad Católica de Chile, Santiago de Chile, Chile, pp. 55-77.

Terrill, Marion (2017), “What price value capture?”, reporte núm. 201705, Grattan Institute, Melbourne, Australia, <http://bit. ly/2wveRe5>, 2 de julio de 2017.

Vejarano, María Clara (2008), "Bogotá, D.C. Primera experiencia de recuperación de la plusvalía urbana para la colectividad, en el marco de la Ley de desarrollo territorial", Architecture, City and Environment, núm. 7, Universitat Politècnica de Catalunya, Barcelona, Espańa, pp. 79-106. 
Recibido: 30 de octubre de 2017. Reenviado: 10 de enero de 2018. Aceptado: 13 de marzo de 2018.

Basilio Verduzco-Chávez. Doctor en Planeación Urbana y Desarrollo de Políticas por la Universidad Rutgers, la Universidad del Estado de Nueva Jersey. Es profesor-investigador en el Departamento de Estudios Regionales-INESER de la Universidad de Guadalajara. Imparte la cátedra de Política Pública y Desarrollo, en el doctorado en Política Pública y Desarrollo del Centro Universitario de Ciencias Económico Administrativas (CUCEA). Es miembro del Sistema Nacional de Investigadores, nivel II. Sus líneas de investigación actual incluyen estudios de planeación y política urbana, análisis de conflicto y negociación en el diseño de política pública y evaluación de impacto social de proyectos de energía. Entre sus últimas publicaciones destacan: Una utopia urbana (im)posible. La negociación infinita de planes urbanos y prosperidad, Universidad de Guadalajara, Guadalajara, México (2013); en coautoría "Fronteras interiores y orígenes del mapa nacional de inseguridad", "Gobernabilidad, migración y redes internacionales del crimen", "Preferencias institucionales y organización de los cuerpos de seguridad", "Prácticas socioespaciales y análisis situacional del delito", "Opciones geopolíticas, racionalidad y seguridad ciudadana en México", en Basilio Verduzco Chávez (coord.), Cada quien su imperio, preferencias institucionales y patrones territoriales de inseguridad, Editorial Universitaria, Universidad de Guadalajara, Guadalajara, México, pp. 17-33, pp. 34-78, pp. 79-104, pp. 160-186, pp. 246255 (respectivamente) (2015).

María Basilia-Valenzuela. Maestra en Desarrollo Regional por El Colegio de la Frontera Norte y maestra en Sociología por The New School For Social Research de Nueva York. Actualmente es profesora del Departamento de Estudios Regionales-INESER de la Universidad de Guadalajara en donde realiza investigación sobre empresarios, distritos turísticos y negocios en comunidades étnicas. Ha publicado en coautoría "Opciones geopolíticas, racionalidad y seguridad ciudadana en México”, en Basilio Verduzco Chávez (coord.), Cada quien su imperio, preferencias institucionales y patrones territoriales de inseguridad, Universidad de Guadalajara, Guadalajara, México, pp. 246-255 (2015). 